\title{
Obras de diversa índole y la fase final de la trans- formación del entorno catedralicio de Ciudad Ro- drigo bajo la dirección de Juan de Sagarbinaga (1761-1792)
}

\author{
Eduardo Azofra \\ Universidad de Salamanca
}

RESUMEN. Al igual que buena parte de las catedrales españolas de origen medieval, el principal templo de Ciudad Rodrigo vivirá a lo largo de la segunda mitad del siglo XVIII, especialmente entre 1761 y 1792 y bajo la dirección de Juan de Sagarbinaga, una época de importantes transformaciones arquitectónicas. Este estudio se centrará en el análisis de las actuaciones menos conocidas y valoradas de las efectuadas en esos años, dejando a un lado, ya ha sido objeto de estudios más pormenorizados, la clasicista renovación llevada a cabo en la imagen catedralicia a poniente, tanto en el exterior, con la portada occidental y la torre, como en el interior, con el trascoro y los retablos de las Once mil Vírgenes y de San Benito.

Palabras clave: Arquitectura. Segunda mitad del siglo XVIII. Juan de Sagarbinaga. Ramón Pasqual Díez. Ciudad Rodrigo (Salamanca). Catedral.

ABSTRACT. Like many of the Spanish cathedrals with mediaeval origins, that of Ciudad Rodrigo went through a period of important architectural changes in the second half of the 18th century, especially between 1761 and 1792, under the direction of Juan de Sagarbinaga. This study will focus on the analysis of the lesser known and valued changes made during that time, leaving aside (since it has already been studied in great detail) the classicist renovation carried out on the Cathedral's western side, both on the outside, with the western door and the tower, and on the inside, with the retrochoir and the reredos of the Eleven Thousand Virgins and of San Benito.

Key Words: Architecture. Second half of century XVIII. Juan de Sagarbinaga. Ramón Pasqual Díez. Ciudad Rodrigo (Salamanca). Cathedral.

\section{NOTA PRELIMINAR.}

Las dos cartas que repletas de noticias sobre Ciudad Rodrigo y su patrimonio artístico incluyera el abate Ponz en su famoso libro de viajes, ambas escritas por dos destacados canónigos de la catedral mirobrigense estrechamente vinculados con el círculo de ilustrados de la ciudad, la primera por Simón Rodríguez Laso y la segunda por Ramón Pasqual Díez ${ }^{1}$, difundie-

\footnotetext{
-
}

${ }^{1}$ Un claro ejemplo del resurgir intelectual y cultural de Ciudad Rodrigo en el último tercio del siglo XVIII fue la creación, impulsada por el grupo de ilustrados que ahí residían, de la Sociedad Económica de Amigos del País de Ciudad Rodrigo, cuyos estatutos, previa solicitud al Consejo de Castilla del 14 de abril de 1780, se aprobaron por real cédula del 27 de noviembre de 1781 , teniendo lugar la primera junta pública el 5 de enero de 1782. Sobre este tema, P. Y J. Demerson, "La Sociedad Económica de ron muy pronto por toda España el nombre del artífice de la portada occidental de la seo rodericense, con decoración de columnas corintias, y de la nueva torre, por cuyo cuerpo bajo se accede a esa puerta del templo, su arquitecto, don

Amigos del País de Ciudad Rodrigo", Cuadernos de Historia Moderna y Contemporánea, 3, 1982, pp. 35-59. Entre los miembros fundadores de esa Sociedad estaban los mencionados Simón Rodríguez Laso, dignidad de maestrescuela de la seo, primer secretario de la Sociedad y posteriormente rector del Colegio Español de la Universidad de Bolonia, y Ramón Pasqual Díez, prebendado de la catedral. Sobre este último vid. R. PASQUAL DÍEZ, El arte de hacer el estuco jaspeado, o de imitar los jaspes a poca costa, y con la mayor propiedad, por ..., racionero de la Catedral de Ciudad Rodrigo, Madrid, 1785. Ed. facs. con estudios introductorios de J. R. NIETO GONZÁLEZ ("El tratadista don Ramón Pasqual Díez", pp. 13-47) y S. MATA PÉREZ ("Los estucos de yeso: el pasado en el presente", pp. 49-66), Valladolid, 1988. 
Juan de Sagarvinaga, individuo de la Real Academia de San Fernando (fig. 1). A partir de ese momento todos los que de una u otra forma se han referido a este edificio se dedicaron a mantener la autoría de esa obra en el haber del arquitecto vizcaíno (que nacido en 1710 en Axpe de Busturia, Vizcaya, moriría en Salamanca en $1797^{3}$ ), ampliando en mayor o menor medida la descripción de la torre, pero sin aportar nuevas referencias sobre los restantes proyectos y trabajos realizados por Sagarbinaga en esa fábrica. Habrá que esperar, como es habitual a la hora de estudiar la vasta producción de este arquitecto en Ciudad Rodrigo, al estudio de Hernández Vegas $^{4}$, quien utilizando como fuente documental las actas capitulares -si bien es cierto que apenas las menciona-, dio a conocer de forma muy completa la activa participación de Juan de Sagarbinaga en el proceso constructivo de la catedral de Santa María durante más de treinta años, desde que fuera llamado por vez primera en abril de 1761 por el cabildo mirobrigense hasta que su nombre aparezca reflejado por última ocasión en las actas capitulares, allá por el mes de mayo de 1792. Y es en estas obras en las que centraremos el siguiente estudio, dejando a un lado, ya han sido recientemente objeto de un estudio más pormenorizado por nuestra parte ${ }^{5}$, la portada occidental y la torre catedralicia, donde Sagarbinaga, considerándolas como una construcción de nueva planta, en toda la extensión de la palabra, actuó siguiendo el criterio de la apuesta por la modernidad o de la adecuación a la sensibilidad de los nuevos tiempos utilizando para ello uno de los lenguajes del clasicismo, el de la recuperación de la arquitectura herreriana; lenguaje que desde muy pronto le cautivó a Sagarbinaga y al que tantas veces acudirá a lo largo de su carrera profesional y que, por otra parte, volvería a ser retomado con inusitada fuerza en la arquitectura española de la segunda mitad del siglo XVIII, dentro de lo que

-

${ }^{2}$ A. Ponz, Viage de España en que se da noticia de las cosas más apreciables, y dignas de saberse, que hay en ella, t. XII, Madrid, 1788, pp. 341 y 343.

${ }^{3}$ E. AzOFRA, El arquitecto Juan de Sagarbinaga (1710-1797), Tesis Doctoral inédita, Salamanca, 2003.

${ }^{4}$ M. Hernández Vegas, Ciudad Rodrigo. La Catedral y la Ciudad, Salamanca, s. a., ¿1935?, Ed. facs., Salamanca, 1982.

${ }^{5}$ E. Azofra, "Criterios de intervención en las actuaciones arquitectónicas acometidas en la catedral de Ciudad Rodrigo en el siglo XVIII", en E. AzOFRA (ed.), La catedral de Ciudad Rodrigo a través de los siglos. Visiones y revisiones, Salamanca, 2006, pp. 523-566 (546-566).
Carlos Sambricio denominó la arquitectura de la Ilustración. En definitiva, todas esas obras, unas y otras, son un claro reflejo del ambiente vivido en las catedrales españolas de origen medieval en la segunda mitad del siglo XVIII, periodo en el que se experimentó un marcado deseo por mejorar y modernizar la arquitectura exterior, también interior, de esas fábricas ${ }^{6}$.

EL PROYECTO DE JUAN DE SAGARBINAGA DE 1761 PARA LA REPARACIÓN DE LAS BÓVEDAS DE LA NAVE CENTRAL Y DE OTROS PARAJES DEL TEMPLO CATEDRALICIO.

El 31 de marzo de 1761, a las doce y cuarto del mediodía, un nuevo terremoto, de menor intensidad que el acaecido en 1755, volvió a sacudir la tierra, ocasionando graves problemas al templo catedralicio. Por ese motivo al día siguiente el cabildo decidió llamar al arquitecto Juan de Sagarbinaga para que registrara el edificio para ber si sus bovedas y demas de su fabrica avian padezido alguna ruina, y que pues se hallava maestro arquitecto subfiziente aziendo la obra de los claustros del Convento de Nuestra Señora de la Caridad, se (le) podia llamar ... pues con eso se saldría de escrupulos y se vería si se nezesitaba hazer algunos reparos para su seguridad y firmeza ${ }^{7}$. Una semana más tarde el reconocimiento no se había efectuado, planteando además el cabildo poco después su deseo de dirigirse al rey, por mediación del marqués de Campo del Villar, solicitándole una pensión, que nunca llegó a obtener, con el fin de hacer frente al cuantioso gasto que iba a suponer la reparación de la catedral. De la misma forma, se optó por requerir a Pedro Bordán, yngeniero maior desta Plaza, una zertificazion del estado y manera que se halla esta Santa Yglesia y la obra y reparos que en ella se deven

\section{-}

${ }^{6} \mathrm{Al}$ respecto siguen siendo fundamentales los trabajos de J. E. García Melero, "Bases metodológicas para el estudio de las transformaciones arquitectónicas de las catedrales góticas", IV Jornadas de Arte. El arte en tiempo de Carlos III, 1989, pp. 125-135; "Realizaciones arquitectónicas de la segunda mitad del siglo XVIII en los interiores de las catedrales góticas españolas", Espacio, Tiempo y Forma, Serie VII, t. 2, 1989, pp. 223-286; "Espiritualidad y estética: las transformaciones en los exteriores de las catedrales góticas españolas durante la segunda mitad del siglo XVIII", Hispania Sacra, 41, 1989, pp. 603-640; Las catedrales góticas en la España de la Ilustración, Madrid, 2002.

${ }^{7}$ Archivo Catedralicio de Ciudad Rodrigo (A.C.C.R.). Actas Capitulares (A.C.), Libro 19, 1 de abril de 1761, f. 40 r. M. HeRnÁNDEZ Vegas, Ciudad Rodrigo..., t. II, p. 268. 
hazer para la maior seguridad, y no padezer una ruina ocasión de muchas desgrazias.

Ese reconocimiento no se debió llevar a efecto y en el cabildo del 22 de mayo (de 1761) se volvía a demandar la presencia de Sagarbinaga (que aparece en la documentación como Juan de Faborbinaga, maestro de obras que está haziendo la de Nuestra Señora de la Caridad), para que lo efectuara y expusiera si la fábrica había padecido algún deterioro de cierta gravedad que, motivado por los temblores producidos esos años, pudiera ocasionar alguna ruina, tanto en el presente como en el futuro, $y$ si dijese se nezesita hazer obra sea por quenta de la fabrica; y sino la gratificazion que se le diese sea por quenta del cavildo y su mesa capitular ${ }^{9}$. Por fin, el 3 de junio se vieron el plan y las condiciones redactadas por el arquitecto vizcaíno, en las que establecía que por aora para la maior seguridad se podía hazer, espresando mui por menor el coste de todos los materiales y manos que podía llegar solo este reparo a la cantidad de 84.000 reales. El proyecto se centraba en la reparación de algunos parajes de la catedral y de las bóvedas, especialmente las de la nave central, las bobedas del medio que caen enzima de las ventanas grandes donde están las bedrieras, que tenían muchas de sus piedras bastante desniveladas, y que de no repararlas podian sobrevenir muchas desgracias. Ante la gravedad de la situación descrita, el cabildo concluyó que sin más dilación se hiciera la intervención planeada por Sagarbinaga, nombrando como comisarios a los canónigos Gaspar Alcrudo y Manuel Avio ${ }^{10}$.

${ }^{8}$ A.C.C.R. A.C. Libro 19, 8, 22 y 23 de abril de 1761, ff. 41 r., 44 v. y 46 r. M. HERnÁNDEZ Vegas, Ciudad Rodrigo ..., t. II, pp. 268 y 292.

${ }^{9}$ A.C.C.R. A.C. Libro 19, 22 de mayo de 1761, ff. 55 v. $-56 \mathrm{r}$.

${ }^{10}$ El canónigo Gaspar Alcrudo ya había actuado en otras obras catedralicias, siendo, por ejemplo, el encargado de llevar a cabo todas las gestiones que fueron necesarias para poder realizar, entre 1748 y 1753, la capilla de Nuestra Señora del Pilar, levantada por disposición testamentaria y tras la muerte de su promotor, el obispo don Clemente Comenge y Avio, que rigió los destinos de la diócesis civitatense desde 1738 hasta 1747 , fecha de su muerte. Sobre este prelado, recogiendo la bibliografía anterior, vid. J. GARCÍA SÁNCHEZ: Procesos consistoriales civitatenses. Miróbriga en los siglos XVII y XVIII, Asturias, 1994, pp. 179-187. Unos años más tarde, en la década de los 60, Gaspar Alcrudo también tuvo una activa participación en la campra de los solares sobre los que se levantó el seminario mirobrigense. Sobre este tema vid. E. AzOFRA, El seminario conciliar de San Cavetano de Ciudad Rodrigo (Salamanca). obra del arquitecto Juan de Sagarbinaga en tiempos de monseñor Cayetano Cuadrillero y Mota, Salamanca, 2004.
Esa situación tuvo que agravarse cuando ese mismo día, a las seis y cuarto, un nuevo temblor de tierra volvió a sacudir el edificio. Así, teniendo en cuenta lo expuesto por el arquitecto, el cabildo acordó trasladar el coro a la capilla mayor para zelebrar las oras canonicas y que se ejecute si se puede componer desde la tarde de este dia de lo que se encarga al señor fabriquero para que de sus providenzias ${ }^{11}$.

El primer paso dado por Avio fue avisar a Juan de Sagarbinaga para que dijese cuánta madera y de qué calidad era necesaria para efectuar la intervención que había propuesto. Después llevó el plan y las condiciones al obispo don José Francisco Biguezal ${ }^{12}$ con el fin de que conociera la obra que el cabildo había decidido hacer en algunas de las bobedas y otros parajes de esta Santa Yglesia quien avia quedado muy gustoso de que el cavildo enprendiese y mandase hazer dicha obra. El 15 de julio (de 1761) se notificaba que había llegado una carta del deán de la catedral de Salamanca en la que indicaba que ese capítulo se avenía a que don Juan Faborbinaga, maestro que está entendiendo en la de la Yglesia de Salamanca viniese también asistir a la obra de esta todo el tiempo que fuese nezesario ${ }^{13}$. A partir de ese momento Juan de Sagarbinaga unirá a su cargo de maestro mayor de las obras de la catedral salmantina (que desempeñará desde noviembre de 1754 hasta enero de 1767, fecha en la que dimitió, entre otras causas, por discrepancias con el cabildo), el de su análoga mirobrigense.

\section{-}

Por su parte, el canónigo Manuel Avio era el hermano del obispo don Clemente Comenge, en cuyo séquito había llegado a Ciudad Rodrigo.

${ }^{11}$ A.C.C.R. A.C. Libro 19, 3 de junio de 1761, ff. 57 v.-59 v. Erróneamente Hernández Vegas (t. II, p. 268) adjudicó al ingeniero Pedro Bordán el reconocimiento del 3 de junio de 1761, cuando en realidad lo efectuó Juan de Sagarbinaga. Además, equivocándose otra vez, fechará el informe del arquitecto vasco a mediados de julio, momento en el que realmente en las actas capitulares se informa de que el cabildo salmantino le concedía a Sagarbinaga su permiso para que asistiera a la obra de la catedral mirobrigense el tiempo que fuera necesario. Este error lo subsanará en parte cuando adscriba a Sagarbinaga el plan de reparación de la fábrica valorado en 84.000 reales (t. II, p. 292).

${ }^{12}$ Este prelado dirigió la diócesis civitatense desde el 22 de julio de 1756 hasta el 2 de diciembre de 1762, fecha de su muerte. Sobre su episcopado, entre otras referencias y recogiendo la bibliografía anterior, vid. J. GARCÍA SÁNCHEZ: Procesos consistoriales ..., pp. 195-199.

${ }^{13}$ A.C.C.R. A.C., Libro 19, 8 y 15 de julio de 1761, ff. 68 r. y 69 r. 
A finales de julio (de 1761) el cabildo acordó que al canónigo Avio se le dieran 10.000 ó 12.000 reales para que, entre otras cosas, comenzara a prevenir los materiales para la obra que se pretendía realizar, con la condición de que llevara cuentas separadas en las que se indicaran lo que se iba gastando para el servicio de la fábrica y para la reparación del edificio ${ }^{14}$. A mediados de agosto, ante la necesidad de efectuar la obra y los reparos de las bóvedas y que la fábrica no se hallaba con caudales para hacerla, el cabildo determinó conceder a los comisarios de obras el permiso para que tomasen a censo el dinero que les pareciese sobre los propios y rentas de la fábrica ${ }^{15}$. A pesar de que en noviembre se insiste en que la catedral se hallaba empeñada en la obra de la iglesia (quizás se trate del abastecimiento de materiales, la madera se depositó en la canóniga), en abril de 1762 el prebendado Avio pone de manifiesto que debido a las novedades que ocurren (se refiere a los temores de una nueva guerra con Portugal), no se avia dado prinzipio a la obra

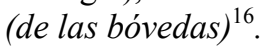

La interrupción de las actas capitulares desde diciembre de 1762 hasta octubre de $1779^{17}$ y las características del tipo de intervención de que se trataba (centrada en la reparación de los problemas tectónicos y estructurales que pudieran presentar las bóvedas, sobre todo las de la nave central, y que difícilmente podía dar pie a que el arquitecto dejara su impronta, y que encaja perfectamente dentro de las obras que efectuadas en los edificios preexistentes ha englobado recientemente Rosende Valdés bajo el epígrafe de restauración ${ }^{18}$ ), plantean dudas acerca de si esos trabajos se llegaron a efectuar, o no, en esos años. En este sentido tampoco ayuda a aclarar el panorama el hecho de que al reiniciarse las actas en uno de sus primeros

\footnotetext{
14 A.C.C.R. A. C., Libro 19, 24 de julio de 1761, f. 73

15 A.C.C.R. A.C., Libro 19, 17 de agosto de 1761, f. 81

${ }^{16}$ A.C.C.R. A.C., Libro 19, 25 de noviembre de 1761, 28 de abril y 12 de mayo de 1762 , ff. 109 v., 142 v. y 147 v.

${ }^{17}$ Se tienen referencias desde mayo de 1773 , pero sólo referidas a los cabildos en los que se trataba sobre los nombramientos de nuevos obispos, canónigos, racioneros, etc.

${ }^{18}$ A. A. Rosende VALDÉS, "La modificación de las tipologías tradicionales en el mundo moderno: la ampliación y reforma de las catedrales gallegas", en M. Á. CASTILLO OREJA (ed.): Las catedrales españolas en la Edad Moderna, Madrid, 2001, pp. 51-84 (53-56).
} v. cabildos, el del 27 de octubre de 1779, se insista en la necesidad que tenía esta iglesia de reparos, y que aunque se havía tratado esto largamente y determinado se reconociese por un maestro, $y$ formase el plan correspondiente con una declaración de lo que debería gastarse ${ }^{19}$, porque aún no se habían efectuado.

De todas formas, creemos que las obras de la nave central sí se materializaron, siguiendo el proyecto de Juan de Sagarbinaga, aunque no podemos determinar en qué fecha exacta ni el dinero que se acabó invirtiendo en esos trabajos, planteándose en 1779 la necesidad de emprender otros nuevos que vinieran a complementar los ya ejecutados. Esta hipótesis se asienta en la circunstancia de que cuando se vuelvan a especificar las obras que se debían realizar ya no se mencionan las bóvedas de la nave central, designándose en los informes $\mathrm{y}$ en los reconocimientos la necesidad de intervenir en otros espacios. Asimismo la propia fábrica, la cornisa dieciochesca que por encima de los contrafuertes medievales finaliza la nave central (fig. 2), pone de manifiesto que esa intervención restaurativa, provocada por un fenómeno natural y que pone de manifiesto que esos organismos vivos que son las catedrales generan una actividad permanente, acabó ejecutándose. Además, esa desornamentada cornisa responde a la perfección al ideario arquitectónico de Juan de Sagarbinaga, que por ejemplo estaba utilizando, es de suponer que por las mismas fechas, una muy similar en la torre catedralicia, levantada entre 1764 y 1770, para delimitar la separación entre el segundo cuerpo y el de campanas.

Si bien es cierto que en la década de los 80 se insistirá en la necesidad de intervenir en las cubiertas de la nave meridional, creemos que también fue en estos años, haciendo uso de la expresión documental algunos parajes de la catedral, y quizás durante el proceso de construcción de la torre, cuando se renovaron, siguiendo el proyecto de Sagarbinaga, las cornisas de las naves laterales y quedaron planteadas sus oportunas balaustradas. De otra manera sería difícil explicar la perfecta sincronía que existe entre las cornisas que rematan las capillas sitas a los pies del templo, la de San Blas a septentrión y la de los Dolores a mediodía, y la configuración de la propia torre, al ser aquellas cornisas una perfecta continuación, o viceversa, de la

${ }^{19}$ A.C.C.R. A.C., Libro 20, 27 de octubre de 1779, s. f. 
línea de imposta que separa los dos cuerpos inferiores de la torre (fig. 1). Del mismo modo, también se deben al proyecto de Sagarbinaga los pedestales de las balaustradas, quizás éstas nunca se llegaron a materializar, que aún lucen sobre esas cornisas (figs. 3 y 4). Esos pedestales, que rematan en unos pebeteros similares a los que aparecen en los retablos catedralicios de las Once mil Vírgenes y de San Benito que, ubicados en el útlimo tramo de las naves laterales y empotrados parcialmente en los muros perimetrales del templos, el primero en el lado del evangelio y el segundo en el de la epístola, hemos puesto recientemente en el haber de Juan de Sagarbinaga, muestran en el frente una moldura que tiene las esquinas matadas en un cuarto de círculo con centro en el exterior, muy característica en el hacer del arquitecto vizcaíno en sus obras mirobrigenses, mientras que en las caras laterales adosa medios balaustres que sirven para hacernos una idea del perfil que hubiesen tenido esas balaustradas de haberse llegado a materializar.

\section{LA RENOVACIÓN DE LA CUBIERTA DE LA SACRISTÍA, UN PROYECTO DE JUAN DE SAGARBINAGA DE 1782 Y NO DE 1792.}

Atravesando la puerta rasgada en el muro norte del ábside del evangelio se accede a la primitiva sacristía, hoy convertida en antesacristía, denominación con la que ya es mencionada en la documentación catedralicia del siglo XVIII, y desde la que se pasa por el vano abierto en su muro oriental a la actual sacristía, cuya planta y muros perimetrales (no sólo las hiladas inferiores sino también otros elementos de cierta consideración), pudieran derivar de la obra aquí levantada en 1583 por Juan de Balbás y tasada por Rodrigo de Ruesga y Pedro de Iturralde (fig. 5). Sin duda, estos dos espacios son en los que Sánchez Cabañas sitúa a comienzos del siglo XVII la sacristía y sagrario, obra moderna y bistosa de media grandeça. Está adornado este sagrario de muchas pinturas y hieroglificos ${ }^{20}$. Ay en medio dél arco laviado en la pared, perfilado de oro, adonde dentro de una rexa se guardan las sagradas reliquias que tiene esta yglesia ... Sobre un altar que aqui ay se bisten los señores prevendados que an de deçir la misa mayor. Al uno y otro lado deste altar ay cajones adonde se guardan los ornamentos frontales $y$

\footnotetext{
${ }^{20}$ Hoy en el muro septentrional de la actual sacristía
} aún se pueden apreciar algunas de esas pinturas. tapicerías, que tiene esta yglesia para el serviçio y culto divino; ... Esta sacristía y sagrario tiene tres apartamientos. En el uno ay un altar adonde en días que ay sermón se diçe misa, porque no se puede salir a la yglesia, ... En el segundo apartamiento se guarda toda la plata, $y$ en el terçero los frontales, roquetes, alvas, ávitos, misales, candeleros y las mangas bordadas de las cruzes que se llevan a las procesiones en las festividades solemnes ${ }^{21}$.

Los consabidos deterioros ocasionados por el paso del tiempo y su continua utilización motivaron que este espacio llegara al último cuarto del siglo XVIII en un pésimo estado de conservación. Así, en 1782 el fabriquero de la catedral, Mateo de los Villares, comunicó al cabildo que havía un devoto que quería componer el cielo de la sacristía, haciendo todo aquello que parezca mas correspondiente para su hermosura, pero que era indispensable el sufrir mucha incomodidad en dicha sacristía por los andamios que necesitaban hacerse, y al mismo tiempo, que conoziendo sería inútil y poco permanente esta obra sino se tomaba alguna providencia con el brasero del quarto de la sacristía. El cabildo acordó que se aceptara esa oferta, dándole las gracias al fiel por su ofrecimiento, $\mathrm{y}$ que se pusiera en ejecución esa obra tomando todas las medidas correspondientes para que durante su realización los sacerdotes se pudieran vestir sin problemas y que incluso, con el fin de llevarla a cabo, que la fábrica corriera con el gasto del andamio si el devoto no se atrevía a hacerse cargo de él. Unas semanas más tarde, con el deseo de que se iniciaran los trabajos, el cabildo decidió que en sustitución del brasero de la sacristía se colocara en algún rincón del claustro una especie de braserillo sólo para el serbicio de los yncensarios y que (se) abilite alguna pieza junto a la contaduría para que puedan en el ymbierno los señores que gusten subir a tomar chocolate, o a otro qualquier fin de que tengan necesidad ${ }^{22}$. $\mathrm{Y}$ es entonces, y no una década más tarde como se ha venido apuntando, cuando se materializó la cubierta que hoy cierra la sacristía, siguiendo posiblemente un proyecto ideado por Juan de Sagarbinaga (en su

${ }^{21}$ A. SÁnCHEZ CABAÑAS, Historia Civitatense, Biblioteca de la Universidad de Salamanca, Manuscritos 1708, 1709 y 1710 . Cito por la edición de Á. BARRIOS GARCÍA E I. MARTÍN VISO, que fecharon la realización de esa obra entre 1618 y 1627 , Salamanca, 2001, pp. 146-147.

22 A.C.C.R. A.C. Libro 20, 7 y 30 de agosto de 1782, s. 
defecto podría pensarse en Ramón Pasqual Díez como su tracista), que en el transcurso de ese año cursó varias visitas a Miróbriga.

En el exterior, fruto de esa intervención, es la sencilla cornisa moldurada que la remata (fig. 6), mientras que al interior la cubierta de este espacio se divide en dos tramos a partir de un arco perpiaño muy rebajado, casi plano, que descansa en dos ménsulas de gran desarrollo que, talladas con gran minuciosidad (fig. 7), lucen en el centro un motivo vegetal. A su vez los dos tramos presentan en su extremo otro arco muy rebajado que apoya en sencillas repisas molduradas y queda enmascarado por las bóvedas de lunetos que, también casi planas, los cierran (fig. 8).

De todas formas esos trabajos no paliaron todos los problemas, algunos muy graves, que venía presentando la sacristía y que se agudizaron una década más tarde. Así, en los cabildos de mayo de 1792 se daba cuenta de la necesidad que había de preserbar la sacristía de las humedades que (procedentes del suelo) perjudican las ropas de la yglesia, exponiendo el fabriquero que mientras se decidía qué trabajos se podían efectuar era conveniente colocar un entarimado para evitar posibles daños. La situación debió ser de tal gravedad -el fabriquero llegó a proponer que los trabajos se empezaran de forma inmediata en atención a la mucha necesidad que tenía de preserbarse de su grande humedad-, que el cabildo determinó que como en breve iba a llegar a la ciudad se le consultara a Juan de Sagarbinaga sobre este tema $^{23}$. Si bien su nombre no vuelve a aparecer en las actas capitulares, es posible que en alguna de las últimas visitas que efectuó a Miróbriga llevara a cabo el correspondiente informe, centrado en dar una solución a los problemas de humedad que presentaba el solado de este ámbito $^{24}$.

\footnotetext{
${ }^{23}$ A.C.C.R. A. C. Libro 22. 10 y 22 de mayo de 1792 , s. f. M. HeRnÁNDEZ VEGAS, Ciudad Rodrigo..., t. II, p. 293.

${ }^{24}$ El actual entarimado deriva de la intervención efectuada en 1948, con presupuesto del Ministerio de Educación Nacional, por el arquitecto Anselmo Arenillas Álvarez. Vid. J. E. DíEZ SÁNCHEZ: "El Plan Director de la catedral de Ciudad Rodrigo. Intervenciones", en E. AzOFRA (ed.), La catedral de Ciudad Rodrigo a través de los siglos. Visiones y revisiones, Salamanca, 2006, pp. 579-605.
}

EL PLAN DE JUAN DE SAGARBINAGA DE 1782, MATERIALIZADO Y QUIZÁS AMPLIADO POR RAMÓN PASQUAL DÍEZ, PARA LA REPARACIÓN DEL SOCALZO Y CUBIERTAS DE LA NAVE MERIDIONAL, DE LAS CORNISAS DE LOS BRAZOS DEL CRUCERO Y LA REFORMA DEL ATRIO DE LA PUERTA DE LAS CADENAS.

El 27 de octubre de 1779, tras exponer que era necesario llevar a cabo obras de cierta envergadura en el templo catedralicio, el cabildo acordó que fuera Juan de Sagarbinaga el que sin más dilación reconociera la fábrica, formara un nuevo plan y tasara los gastos de esos trabajos, si está a la sazón en esta Ciudad o se espere su venida para que lo ejecute de orden del Cavildo y se bayan haciendo las prebenciones de materiales y más necesario sin perder más tiempo ${ }^{25}$. No creemos que Sagarbinaga llegara a efectuar en esas fechas ese encargo, sus compromisos en Salamanca y la obra del cuartel militar de Medina del Campo le debieron impedir hacer otros viajes a lo largo del año 1780. Así, el 29 de marzo de 1781 el fabriquero indicaba al cabildo la necesidad tan grande que tenía la fábrica de esta Santa Yglesia de reparos y que aunque se habian dado barias órdenes del cabildo para que se ejecutasen no habian tenido efecto, lo que recordaba al cabildo para que diese las probidencias que tubiese por combenientes. El cabildo decidió que el fabriquero, acompañado entre otros por Ramón Pasqual Díez, el comisario de obras de la catedral, se viera con Sagarbinaga e inspeccionaran detenidamente quanto ay que reparar, se hicieran cargo del aprovisionamiento de los materiales que se necesitaran para todo lo que se proyectara y si lo tubiesen por combeniente manden lebantar plan y evaquado se traiga a cabildo para determinar lo que más combenga ${ }^{26}$. El 29 de mayo el fabriquero determinaba que era preciso componer algunos balaustres del balconcillo de la torre nueva, el arco que cae sobre la puerta de las Cadenas, donde estaba la máquina del reloj ${ }^{27}$, como así mismo la

25 A.C.C.R. A.C. Libro 20, 27 de octubre de 1779, s. f. M. HERnÁNDEZ VEGAS, Ciudad Rodrigo..., t. II, p. 293.

${ }^{26}$ A.C.C.R. A.C. Libro 20, 29 de marzo de 1781, s. f. M. M. HeRnándeZ VeGAS, Ciudad Rodrigo..., t. II, p. 293.

${ }^{27}$ Hasta la construcción de la torre ideada por Sagarbinaga, el último lugar en el que había estado colocado el reloj de la catedral había sido en el muro oriental del brazo sur del crucero, encima del retablo de San Miguel. Así lo describía Sánchez Cabañas (p. 138): ... y sobre el altar de San Miguel está el artifiçio del relox, en el qual se ve creçer y 
que tenían los tejados de que tanto se ha tratado hasta ahora. En este caso se optó porque se fuera reparando sólo lo más preciso hasta que se ejecutara un nuevo plan de toda la obra que se requería llevar a cabo ${ }^{28}$.

Ramón Pasqual Díez presentó el 23 de enero de 1782 el plan formado por Juan de Sagarbinaga para la obra que necesita hazerse en la nabe colateral del mediodía de esta Santa Iglesia, y la regulación que hizo de sus matheriales y parte de manos, asciende a 21.716 reales de vellón. Al mismo tiempo, en atención a la necesidad que tiene dicha nabe de esta obra según expresa referido maestro arquitecto, el cabildo determinó dar amplias facultades al comisario de obras, que actuará en esta empresa como un auténtico aparejador a pie de obra, para que hiciera las reparaciones que se establecían en el plan del vizcaíno, tomando para ello los medios y prevenciones que creyera más oportu$\operatorname{nos}^{29}$. Posteriores referencias nos llevan a pensar que el proyecto de Sagarbinaga planteaba una completa intervención en toda la nave meri-

menguar el sol y la luna a la medida y compás que llevan en el çielo, lo qual a quien lo mira caussa admiración y se echa de ver el gran ingenio que tenía el maestro que lo hizo. $\mathrm{Al}$ ser trasladado a la nueva torre, los vestigios que quedaron de él en su antigua ubicación crearon algunos problemas tectónicos que rápidamente se solucionaron, como se referirá más tarde.

28 A.C.C.R. A.C. Libro 20, 29 de mayo de 1781, s. f.

29 A.C.C.R. A.C. Libro 20, 23 de enero de 1782, s. f. M. HeRnÁNDEZ VegAs, Ciudad Rodrigo..., t. II, p. 293. La elección de Ramón Pasqual Díez como comisario de obras y aparejador, en determinados momentos incluso puede que actuara como proyectista, no fue ni mucho menos casual, debido a la experiencia que ya atesoraba en este campo, al haber actuado años antes como aparejador-director de las obras del seminario conciliar y su iglesia y de las de la crujía sur del palacio episcopal, que también había ideado Sagarbinaga (E. AzOFRA: El seminario conciliar ... y E. AzOFRA: El arquitecto Juan de Sagarbinaga ..., pp. 655-656). Además, los compromisos que durante esos años tuvo el arquitecto vasco motivaron que sus visitas a Ciudad Rodrigo se redujeran drásticamente, causa por la que los diferentes comitentes tuvieron que recurrir a otros maestros para que realizaran los proyectos que había ideado y llegado el momento para que proyectaran otros nuevos. El papel que desempeñó Ramón Pasqual Díez en las obras catedralicias efectuadas entre 1780 y 1785 también fue destacado por J. R. NiETO GONZÁLEZ ("El tratadista don Ramón Pasqual Díez..., en Arte de hacer el estuco jaspeado ..., pp. 21-22) al apuntar que fue el encargado por el cabildo de supervisar en unos casos y de dirigir en otros las obras catedralicias: restauraciones de las bóvedas, trabajos en los atrios de las Cadenas y del Enlosado, tejados de las capillas del crucero, ... Particular importancia tuvo la reforma de la fachada y nave del mediodia que debia estar finalizada en 1784 y que fue presupuestada por el canónigo. dional, tanto en el socalzo como en la cubierta, afectando incluso a la fachada y puerta de las Cadenas, donde el espacio en el que se ubicaba el reloj de la catedral con anterioridad se convirtió en uno de los aspectos a los que hubo que buscarle una rápida solución ${ }^{30}$. De todas formas, el incremento que se produjo en el gasto de las obras sobre el presupuesto inicial dado por Juan de Sagarbinaga nos hace suponer que en el transcurso de los trabajos Ramón Pasqual Díez también pudo haber añadido alguna modificación, ya más como tracista que como aparejador, que quizás no estaba, o sí, reflejada en el proyecto inicial de Sagarbinaga $^{31}$.

La obra ideada por Sagarbinaga se inició inmediatamente, hallándose abierta en mayo (de 1782), momento en el que la fábrica carecía de caudales para poder continuarla, pero como si se optaba por suspenderla el coste sería mucho mayor cuando se decidiera reanudarla, el cabildo opinó que se aplicaran a esos trabajos los maravedís sobrantes de casas escusadas o reclamadas por vía de emprestito, con calidad de reintrego, y con la obligación de entregar a las partes o parte ynteresada en ellos, que lo reclame con derecho y justicia la cantidad que resulte debérsele por el repartimento general de este ramo ${ }^{32}$. A mediados de mayo el aparejador de la obra expuso como se iban desarrollando los trabajos y que no estaba decidido a realizar los que se manifiesta se precisan en la fachada y puerta de las Cadenas, tanto en el pie como en lo alto de ella, por no poder asegurar el costo que en lo último puede tener, exponiendo para

${ }^{30}$ Así, en agosto de 1782, Ramón Pasqual Díez indicaba al cabildo que se hallaba abierta una ventana donde antes estaba el reloj de la catedral y que deseaba saber si tenía que hacer en ella algún óvalo o cerrarla; posibilidad ésta segunda que consideraba mucho más acertada tanto por motivos económicos, atendiendo al estado de gastos en que se halla la iglesia, como estructurales, para mayor seguridad de la pared, y estéticos, la ninguna uniformidad que causa. El cabildo, teniendo en cuenta todas las causas expuestas por el comisario de las obras, acordó que se cerrara lo antes posible, como así se hizo, esa ventana. A.C.C.R. A.C. Libro 20, 7 de agosto de 1782 , s. f.

${ }^{31}$ El hecho de que no exista ninguna nota que nos pueda servir de referencia para establecer algún aspecto significativo del proyecto redactado por Juan de Sagarbinaga, referido siempre de una forma muy genérica, nos plantea importantes dudas a la hora de discernir si las supuestas ampliaciones introducidas por Ramón Pasqual Díez ya habían sido contempladas por el arquitecto vizcaíno.

${ }^{32}$ A.C.C.R. A. C. Libro 20, 11 de mayo de 1782, s. f. 
ello varias causas y razones ${ }^{33}$. Enterado el cabildo convino que se prosiguiera la obra según las ydeas que tiene proyectadas y que, desde nuestro punto de vista, formaban parte del plan trazado por Sagarbinaga. Así, en los primeros días de julio se leía en el ayuntamiento una petición de Ramón Pasqual Díez, en la que, tras exponer que con el fin de mejorar el aspecto y la comodidad de la entrada sur del templo era necesario demoler el actual atrio y colocar en él la escalera que hoy se encontraba en el interior de la catedral ${ }^{34}$, planteaba que para llevar a cabo esa obra era necesario tomar algún terreno de la calle, dos varas de terreno publico de ancho con el largo correspondiente para incorporar como indispensables en la obra y mutación de atrio que esta haciendo, dando buelta con la correspondiente disminución en linia hasta el tercer estribo de la capilla mayor, de cuia concesión no resultaba perxuicio al tránsito de las gentes por la suficiente capacidad que se nota. El concejo, tras el informe de los comisarios de ejidos en el que indicaban que no había ningún menoscabo para la ciudad, acordó concederle francamente dicho terreno, precedida demarcación, dando muestra así de su deseo de contribuir por su parte a quanto sea en ermosura, aseo, y mejor aspecto de dicha Santa Yglesia y obsequio de su Ylustre Cavildo ${ }^{35}$.

En julio de ese mismo año, 1782, se volvía a apuntar que se precisaba dinero para poder continuar al haberse gastado ya los últimos 16.000 reales de las segundas casas reclamadas que se mandaron entregar al Señor Díez. Por ese motivo el cabildo decidió adjudicar el dinero que aún quedaba en el archibo, así de fábrica y

33 A.C.C.R. A.C. Libro 20, 16 de mayo de 1782, s. f. M. HeRnÁndez Vegas, Ciudad Rodrigo..., t. II, p. 300.

${ }^{34}$ Hasta que se llevó a cabo esta intervención al acceder al interior de la catedral por la puerta de las Cadenas era necesario bajar, ya en el interior, diez gradas, como recoge a principios del siglo XVII el propio Sánchez Cabañas, p. 142. Por otra parte, cabe reseñar que este tipo de intervención también fue realizada en otras catedrales españolas en las mismas fechas, en el último tercio del siglo XVIII. Sobre este tema, entre otros, vid. J. E. GARCÍA MELERO, "Espiritualidad y estética...", Hispania Sacra, 41, 1989, pp. 603640; Las catedrales góticas..., Madrid, 2002. De todas formas, quizás, el ejemplo más significativo fuera el de la catedral de Burgos. Para este caso, entre otras referencias, vid. A. B. Nieto PlazA, "La obra de la puerta de Santa María en la catedral de Burgos (1790-1791)", Boletín de la Institución Fernán González, 219, 1999/2, pp. 339-376.

35 Archivo Histórico Municipal de Ciudad Rodrigo (A.H.M.C.R.). Libro de Acuerdos (L.A.). 1782. Consistorio del 3 de julio, ff. 75 r. y 76 v.-77 r. obras pías como de algún otro rramo, con (la condición de que se realizara una) especificación indibidual de cada partida. Apenas unos días más tarde se dejaba constancia de que al comisario de la obra se le concedían todos los fondos existentes, que suponían 20.724 reales $^{36}$. Pero, el 21 de agosto, Ramón Pasqual Díez advertía al cabildo que si deseaba proseguir la obra debía buscar más caudales para que quando llegue el caso de que el último dinero que se le entregó se concluya, tubiese dispuesto ya el cabildo lo que se havía de hazer, o le diese las órdenes de quanto convenía practicar. Por su parte, el cabildo le requirió que regulara el costo que podía tener concluir toda la obra que resta$\mathrm{ba}^{37}$.

El 4 de septiembre de 1782 se presentó la regulación a la que ascendía la obra proyectada por Ramón Pasqual Díez. Así, estableció, echándolo algo por lo alto, que para finalizar el atrio de la Puerta de las Cadenas, sacar todos los escombros y poner sus remates se necesitarían 9.600 reales; que poner, labrar y macizar las quatro yladas de piedra de la cornisa que son de cinquenta (varas) de línea, 9.896 reales; que por las cinquenta varas de valaustres con las pilastras correspondientes, 3.500 reales; que por el socalzo y atrio de la puerta del Enlosado en la misma conformidad que el de las Cadenas, y poner los valaustres que faltan serían menester 12.800 reales, y ultimamente que para echar el tejado a todas las capillas del cruzero 10.500 reales. El cabildo, carente de recursos económicos, acordó que por el momento sólo se concluyera la obra comenzada en lo alto y bajo de la Puerta de las Cadenas, su atrio, hiladas de piedra y balaustres, cuyo coste ascendía a 22.996 reales, y que además para hacer frente a él el estuquista ya tenía alguna cantidad de maravedis en su poder ${ }^{38}$.

El 13 de noviembre Ramón Pasqual Díez advertía al cabildo que no podía seguir con el encargo adquirido, asi por falta de salud como por la de dineros. El cabildo, tras lamentar la enfermedad del maestro, le proponía que por $s u$ maior inteligencia en la obra continuara dirigiendo los trabajos aunque fuera desde la cama,

-

${ }^{36}$ A.C.C.R. A.C. Libro 20, 16 y 24 de julio de 1782, s. f.

${ }^{37}$ A.C.C.R. A.C. Libro 20, 21 y 30 de agosto de 1782, s. f.

38 A.C.C.R. A.C. Libro 20, 4 de septiembre de 1782, s. f. M. HERnÁNDEZ VEGAS, Ciudad Rodrigo..., t. II, p. 300. 
y que a pesar de lo apurada que estaba la fábrica de caudales aún se le podían entregar 3.000 reales más para que la prosiguiera ${ }^{39}$. A pesar de ese nuevo estímulo económico, el cabildo, cuando aún no habían transcurrido ni tan siquiera diez días, se vio obligado a sacar del arca de las obras pías del obispado otros 8.000 reales con el fin de asegurar la continuación de la obra y que así no se parase como ya tenía resuelto el referido R. Pasqual Díez ${ }^{40}$.

El 11 de diciembre de 1782 el cabildo tenía conocimiento de un nuevo plan formado por el estuquista en el que tasaba en 77.693 reales los trabajos que restaban para acabar de perfeccionar la obra que se estaba efectuando. Una vez más, como ya había ocurrido con anterioridad, el cabildo le instó a que por ahora sólo se dedicara a concluir el atrio de la puerta de las Cadenas en la forma ya ydeada y aprobada, y que a causa del quebranto que padecía su salud, según apareze de la certificazion de médico que presenta, se le concedieran unos días, dos semanas, de recreación para su restablecimiento ${ }^{41}$.

Finalmente el 21 de mayo de 1783, época en la que se paralizaron los trabajos definitivamente por causas económicas, el racionero Ramón Pasqual Díez presentó la cuenta general de las obras hechas en la catedral bajo su dirección, cuyo coste ascendía a 75.316 reales, y una completa relación de ellas: se socalzó la yglesia de piedra berroqueña desde la torre nueba (es decir, la actual) hasta la capilla del Santo Christo del Oriente (se trata del ábside de la nave de la epístola), rebajando hasta ella la calle y el atrio, quitando de lo interior de la iglesia siete pasos que tenía de bajada, dejando fuera los que oy se ben, haciendo todo el atrio, con sus pilastras y balconaje, demoliendo lo que habia sobre esta puerta de la torre vieja, se quitaron varias yladas de piedra y se pusieron nuebas, con todo el cornisamiento y albardillas, haziendo esto mismo en el cruzero en la parte que mira al claustro, y concluido el atrio que fue lo último que se hizo paró la obra por falta de dinero, quedando preparadas las maderas para

${ }^{39}$ A.C.C.R. A. C., Libro 20, 13 de noviembre de 1782, s. f. M. HeRnÁndeZ Vegas, Ciudad Rodrigo..., t. II, p. 300.

${ }^{40}$ A.C.C.R. A.C. Libro 20, 13 de noviembre de 1782, s. f.

${ }^{41}$ A.C.C.R. A.C. Libro 20, 11 de diciembre de 1782, s. f. M. HeRnándeZ Vegas, Ciudad Rodrigo..., t. II, p. 300. los tejados del crucero y los de la nave lateral del mediodía, con más alguna piedra ${ }^{42}$.

Y son algunas de estas obras las que nos siguen creando ciertas dudas a la hora de determinar la autoría del proyecto. A nuestro entender los planes redactados por Juan de Sagarbinaga, especialmente el segundo, el de 1782, ya debía de contemplar aspectos básicos del que posteriormente acabó haciendo Ramón Pasqual Díez, como podía ser el socalzo del templo desde la torre nueva hasta la capilla del Cristo de Oriente, el desmantelamiento de los restos que quedaban de la torre vieja sobre la puerta de las Cadenas $^{43}$ y la realización de una nueva cornisa con su correspondiente balaustrada como remate de las fachadas meridional y septentrional a semejanza de los restos que de ellas quizás quedaran y de la que servía de término del ábside central, ideada por Rodrigo Gil de Hontañón como parte de la intervención que dio origen a la actual capilla mayor, levantada entre 1540 y $1550^{44}$. En este caso Juan de Sagarbina-

42 A.C.C.R. A.C. Libro 20, 21 de mayo de 1783, s. f. M. HeRnández Vegas, Ciudad Rodrigo..., t. II, p. 300. Examinadas las cuentas de esta obra resultaron a favor de Ramón Pasqual Díez 21.465 reales, cantidad y pago que debió asumir Mateo de los Villares, canónigo fabriquero de la catedral. Vid. A.C.C.R. A.C. Libro 20, 4 y 14 de junio de 1783 , s. f.

${ }^{43}$ Recientemente hemos defendido, en contra de la bibliografía que al respecto existe sobre la catedral de Ciudad Rodrigo, que la torre que después de los terremotos de 1755 y 1761 quedó cuarteada en su totalidad y amenazando ruina inminente se levantaba sobre el brazo meridional del crucero. Su estado debía ser tan lamentable que el cabildo decidió que se desmontara con gran celeridad, al menos la parte más peligrosa, y que se proyectara una nueva, la actual, a los pies de la nave central, encomendándole ambas obras a Juan de Sagarbinaga. Sobre este tema vid. E. AzOFRA, "Criterios de intervención ...”, en E. AzOFRA (ed.), La catedral de Ciudad Rodrigo ..., Salamanca, 2006, pp. 523-566.

${ }^{44}$ A. Casaseca Casaseca, Rodrigo Gil de Hontañón (Rascafría, 1500-Segovia, 1577), Salamanca, 1988, pp. 111114. El proyecto de Rodrigo Gil de Hontañón contemplaba la realización de las cornisas y sus correspondientes balaustradas en los brazos del crucero, como, por otra parte, se ejecutaron. Así las describe Sánchez Cabañas (p. 140): quando se labró la capilla mayor,... adornaron el templo por lo alto de corredores y balaustres, hasta las dos puertas colaterales del crucero. Y lo demás de la yglesia se dejó sin hechar la cornixa, como oy se ve. Es de suponer que los fenómenos naturales ya citados, los terremotos de 1755 y 1761, los diferentes avatares históricos acaecidos en Ciudad Rodrigo o el establecimiento en el brazo sur del crucero de la torre de campanas tras los avatares del episodio de las Comunidades (sobre este tema, recogiendo además la bibliografía existente hasta el momento, vid. J. I. MARTín BENITO Y R. GONZÁLEZ RODRíGUEZ: "Lucha de bandos y beneficios eclesiásticos en los encastillamientos de Ciudad Rodrigo (1475-1520)", Studia Historica. Historia Medieval, 
ga, y es el aspecto que más nos interesa destacar, volvía a actuar aplicando con claridad meridiana el criterio de la unidad de estilo, de la pureza artística, en definitiva de la concinnitas vitrubiana o la conformità o convenienza albertiana en la posibilidad de continuar un edificio en su mismo estilo con el fin de lograr su total correspondencia, al que el arquitecto vizcaíno recurrió a lo largo de su obra siempre que consideró que el proyecto así lo requería ${ }^{45}$. Por otra parte, aunque es cierto que la realización del atrio de la puerta de las Cadenas (fig. 9) bien pudo ser contemplada por Juan de Sagarbinaga, que con anterioridad había comenzado la renovación del entorno catedralicio con la realización de la portada occidental y su correspondiente atrio $^{46}$ (fig. 1), posiblemente éste aspecto de la intervención hecha entre 1782 y 1783 deba ponerse en mayor medida en el haber de Ramón Pasqual Díez. En definitiva, fruto de esa actuación se quitaron del interior del templo, como explicaba el propio racionero estuquista, los

17, 1999, pp. 263-293), pudieron motivar su completa o parcial destrucción, haciendo por ello necesaria su restauración.

45 Después de la actuación de Sagarbinaga, tenemos constancia de que en la crestería que corona al exterior la capilla mayor y los brazos del crucero se repusieron una serie de piezas en la intervención efectuada por el arquitecto Anselmo Arenillas Álvarez en 1948 con presupuesto del Ministerio de Educación Nacional. Por su parte, en las obras efectuadas en la Fase II del Plan Director, finalizada en octubre de 2002, debido al lamentable estado que presentaban, perjudicando la estanqueidad del edificio y su definición arquitectónica, se restauró íntegramente la cornisa, consolidando lo que era necesario y reponiendo lo que faltaba, y se recuperaron los tramos de la balaustrada de los que se tenía constancia que habían existido, consolidando y labrando única y exclusivamente los elementos seriados, aplicando en este sentido principios propios de la restauración histórica. Vid. J. E. DíEZ SÁNCHEZ: "El Plan Director...", en E. Azofra (ed.), La catedral de Ciudad..., pp. 579-605.

${ }^{46}$ En mayo de 1772 se leía en el consistorio mirobrigense un memorial del canónigo fabriquero, don Pedro de Naba, en el que se exponía que una vez finalizadas la nueva portada occidental y principal de la catedral, que es la que esta por bajo de la Torre Nueba, el cabildo pretendía, para mas hermosura y dezenzia, realizar delante de ella el atrio que estaba proyectado, sin duda, por Juan de Sagarbinaga, y para el que era imprescindible que el concejo señalara en aquella calle el terreno nezesario para ello, respecto que dicha fabrica no impide el uso, y serbentía, de las pocas casas que en ella existen. Una vez más, el ayuntamiento, con el fin de contribuir al aseo y hermosura de dicha Santa Yglesia, acordó que Andrés Carrillo y Bernardo de Amezti, comisarios de ejidos y terrenos concejiles, reconiceran y delimitaran el espacio que fuera necesario para hacer el referido atrio y se lo entragaran al señor Pedro de Naba, en nombre de Su Santa Yglesia. A.H.M.C.R. L.A. 1772-1773. Consitorio del 27 de mayo de 1772, f. 49 r. siete pasos que tenía de bajada, y se materializó, utilizando para ese fin el espacio público que el ayuntamiento cedió al cabildo tras su solicitud, el atrio tal y como hoy lo seguimos viendo. Delimitado por nueve fustes pétreos (que, concebidos a modo de columnas bajas con remate moldurado, se disponen cuatro a cada lado, es decir, a naciente y a mediodía, y uno más en el ángulo de unión), a él se accede bajando cuatro o tres escaleras, dependiendo de si lo hacemos por el este o por el surr ${ }^{47}$.

\section{EL INFORME DE JUAN DE SAGARBINAGA SOBRE EL PLAN IDEADO POR RAMÓN PASQUAL DÍEZ EN 1785 PARA LA REPA- RACIÓN DE LOS TEJADOS DEL CRUCERO Y LA CAPILLA MAYOR Y LA CONCLU- SIÓN DE LA TRANSFORMACIÓN DEL ENTORNO CATEDRALICIO: LA PUERTA DEL ENLOSADO.}

En el estado de las obras descrito por Ramón Pasqual Díez en mayo de 1783 se insiste en que los tejados del crucero y de la nave meridional todavía no se habían reparado, habiendo quedado preparadas las maderas y algunas piedras para su realización. En el mes de julio de 1783 se insiste en diferentes cabildos para que el fabriquero cuide de todos los materiales que habían sobrado, instándole a que los pusiera en un lugar seguro con la finalidad de evitar que se pudrieran o quedaran inutilizados, hasta que se resolviera qué hacer sobre la continuación de la obra planeada e iniciada en la catedral. Se decide que este tema vuelva a ser tratado en la primavera venidera, encargando entonces nuevos informes a personas inteligentes, pero teniendo presente en todo momento la regulación del coste hecha por Ramón Pasqual Díez ${ }^{48}$.

De todas formas, habrá que esperar hasta abril de 1785, momento en el que el fabriquero, Mateo de los Villares, recordó que era muy preciso concluir la obra de los tejados del edifi-

${ }^{47}$ En 1900 el cabildo sufragó la sustitución de las escalinatas, que hasta entonces eran de arenisca, enlosando además con granito el acceso al templo. En 1948 Anselmo Arenillas, en la intervención ya referida en otras ocasiones, reparó este enlosado dándole la vuelta a las losas y relabrándolas. Por último, este espacio ha sido restaurado dentro de las obras efectuadas en la Fase III del Plan Director, finalizadas en febrero de 2006. Sobre estos aspectos vid. J. E. DíEz SÁNCHEZ: "El Plan Director...", en E. AZOFRA (ed.), La catedral de Ciudad ..., pp. 579-605.

${ }^{48}$ A.C.C.R. A. C. Libro 20, 9, 19 y 23 de julio de 1783, s. f. M. HERNÁNDEZ Vegas, Ciudad Rodrigo, t. II, p. 300. 
cio que se hallaban bastante deteriorados, para que el cabildo acordara que se ejecutase la obra expresada, empezando por el acopio de los materiales que eran necesarios ${ }^{49}$. Tres semanas más tarde el canónigo de los Villares presentó ante el cabildo el plan y las condiciones para la obra del templo, que cabe suponer que fue redactado por Ramón Pasqual Díez y cuyo coste ascendía a 64.000 reales. El cabildo, tras estudiarlo, decidió nombrar para que tutelaran y controlaran los trabajos y sirvieran de segundos maestros a Francisco Pereira, que asumirá la dirección recibiendo 7 reales diarios de sueldo, incluyendo también los festivos, y a Miguel de la Piedra, que asistirá como oficial, principiando sin detención alguna los tejados del cruzero y capilla maior; y que el ajente Ramón Frexe cuide de pagar semanalmente a los oficiales $y$ peones poniendo el señor fabriquero en su poder los dineros necesarios. Además, con el fin de aclarar algunas dudas y dificultades que se advertían en el proyecto -asi en el tejado del cuerpo de la yglesia, en los de los colaterales si han de ser de mazizo o de madera, en las salidas de las aguas, etc.-, el cabildo acordó que se le consultaran, al igual que todo el plan, a Sagarbinaga, que estaba en Medina del Campo, enviándole con una persona la documentación y las cuestiones que se les presentaban a los canónigos, como así debió de suceder, y que se escribiera a fray Andrés para que viniera cuanto antes al último reconocimiento y a dictaminar sobre todo lo que se había dicho ${ }^{50}$.

Este proyecto, y por tanto sus pertinentes informes, debió de ser bastante más complejo y no sólo afectó a la obra de los tejados del crucero y de la capilla mayor sino que fue en ese momento cuando los trabajos se centraron fundamentalmente en el atrio de la puerta del Enlo-

${ }^{49}$ A.C.C.R. A.C. Libro 20,6 de abril de 1785 , s. f.

${ }^{50}$ A.C.C.R. A.C. Libro 20,27 de abril de 1785 , s. f. M. HERNÁNDEZ VEGAS (t. II, pp. 293 y 300-301) ya reseñaba la extrañeza que le causaba el hecho de que estando aún en Ciudad Rodrigo el racionero Ramón Pasqual Díez, no se le mencionara en esta obra. Por nuestra parte, ya hemos apuntado que el autor del proyecto pudo ser él, quien además creemos que quizás solicitara al cabildo en esas fechas poder liberarse de asumir la dirección de esos trabajos -en la documentación se habla de nombrar los sujetos que han de dirigir dicha obra, y serbir de segundos maestros-, con el fin de disponer de más tiempo para poder hacer frente a la conclusión y publicación de su tratado sobre el Arte de hacer el estuco jaspeado ...., editado en Madrid en ese año de 1785; es decir, en el momento en el que los trabajos de la catedral iban a estar en su máximo apogeo. sado o de Amayuelas, que quedó configurado entonces tal y como hoy lo comocemos ${ }^{51}$ (figs. 10 y 11). A partir de Hernández Vegas, que como única fuente documental se sirvió de las actas capitulares (que vuelven a tener una importante laguna que va desde 1786 hasta 1790 , ambos años incluidos), se ha venido admitiendo su hipótesis según la cual debía suponerse que en el año 1784 se concluyó la obra del atrio del Enlosado ${ }^{52}$, cuando en realidad en 1786 apenas se había iniciado aún la actividad constructiva, momento en el que el fabriquero Mateo de los Villares requirió al ayuntamiento que le cediera un pedazo de terreno concegil para dar mejor entrada y estension a la puerta que mira para la muralla y plazuela de Amayuelas. Una vez más, como unos años antes había ocurrido en la realización de los atrios de poniente y de las Cadenas, el consistorio rodericense otorgó al cabildo la concesión del terreno que solicitó al no producirse ningún perjuicio común ni particular por quedar vastante capacidad para la entrada y salida de coches y carros por la calle de $\mathrm{Ca}$ $\operatorname{dimus}^{53}$. A este espacio, que queda acotado por sus dos lados por un sencillo banco corrido de granito, se accede bajando por tres escaleras de seis peldaños, una situada a naciente y las otras dos a septentrión. Las obras debieron transcurrir a buen ritmo, porque en 1788, cuando se publica el tomo XII del Viaje de España de Ponz, el propio Ramón Pasqual Díez afirma en la carta que le envió al abate, y que éste incluyó en su obra, que para entrar en la iglesia por las puertas del crucero, se bajaban diez escalones, que causaban deformidad, y se han quitado a instancias de un amigo de usted ${ }^{54}$. Y, de esta forma, en Ciudad Rodrigo también se cumple, siguiendo a Bonet Correa, una de las máximas de las catedrales españolas, la que afirma que la transformación de los entornos catedralicios finaliza en el siglo XVIII ${ }^{55}$.

-

${ }^{51}$ Este atrio será restaurado, como estaba proyectado, dentro de la Fase IV del Plan Director, una vez conluya la exposición Kyrios. Las Edades del Hombre.

${ }_{52}$ M. Hernández Vegas, Ciudad Rodrigo..., t. II, p. 301.

${ }^{53}$ A.H.M.C.R. L.A. 1786. Consistorios del 3 de junio y 12 de julio, ff. 39 r. y $53 \mathrm{v}$

${ }^{54}$ A. PonZ, Viage de España ..., t. XII, Madrid, 1788, p. 346.

${ }^{55}$ A. BONET CORREA, "La catedral y la ciudad histórica”, en M. Á. CASTILlo OrejA (ed.): Las catedrales españolas en la Edad Moderna, Madrid, 2001, pp. 11-26 (19). 


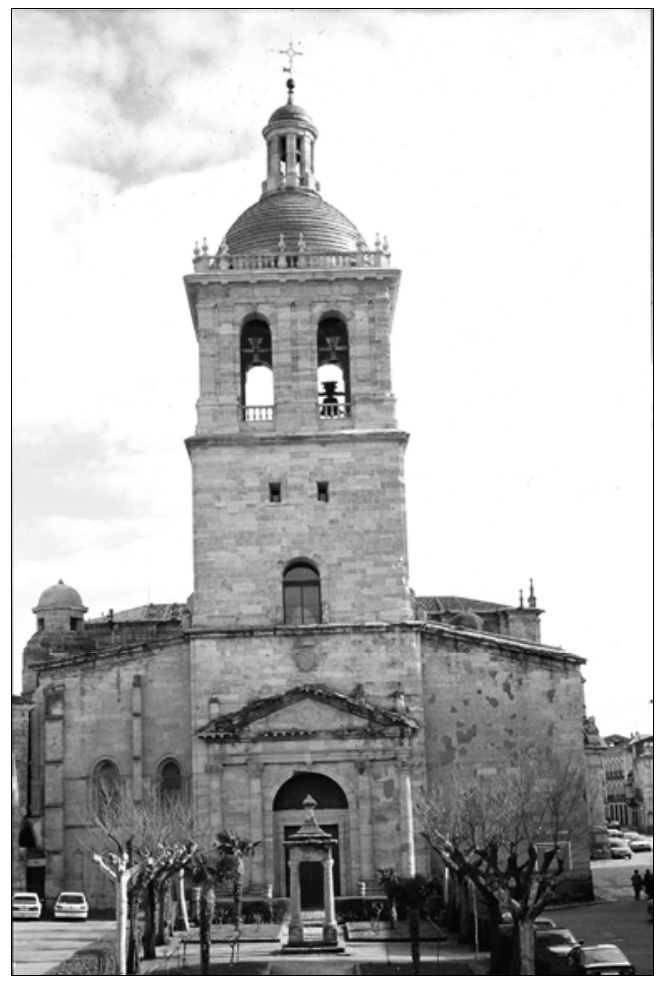

- Fig. 1. Ciudad Rodrigo. Catedral. Torre y portada occidental.

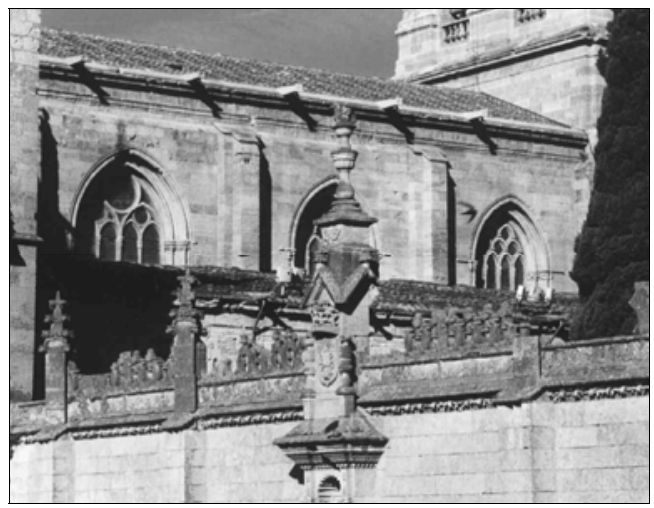

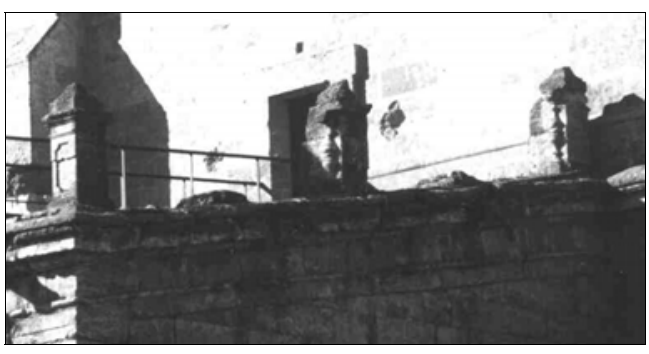

- Fig. 3. Ciudad Rodrigo. Capilla del Sagrario. Balaustrada.

- Fig. 2. Ciudad Rodrigo. Catedral. Nave central. Lado norte.

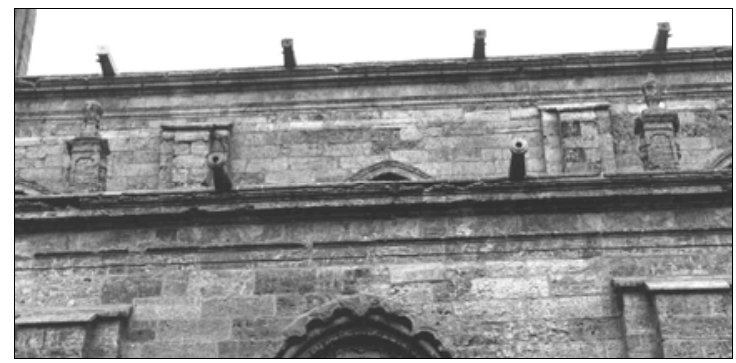

- Fig. 4. Ciudad Rodrigo. Catedral. Nave central y de la epístola. Lado sur. 


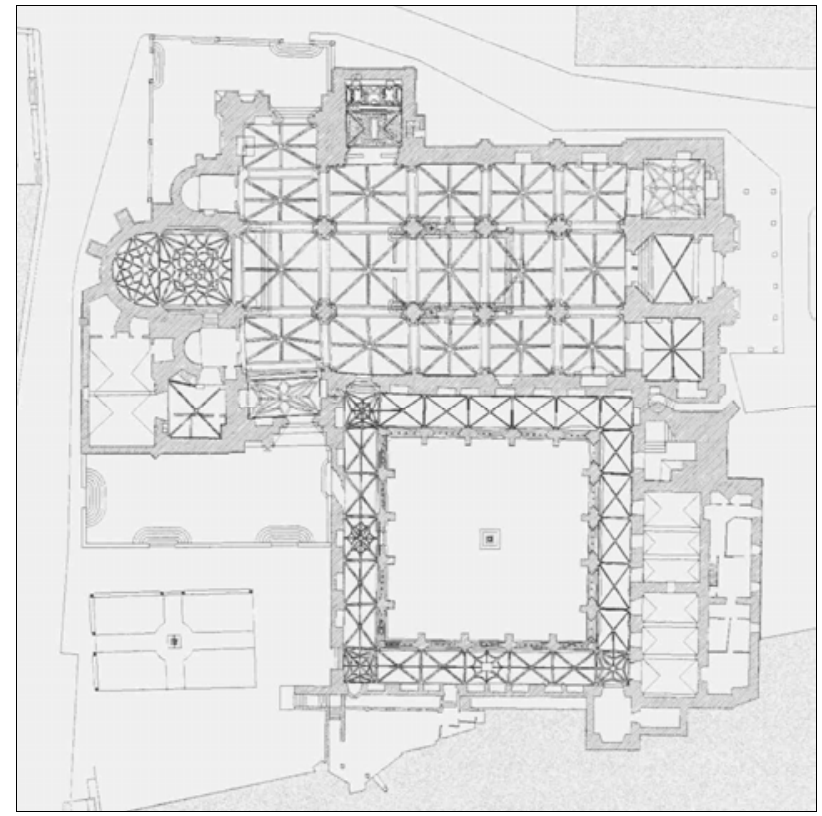

- Fig. 5. Ciudad Rodrigo. Catedral. Planta, según J.E. Díez Sánchez.

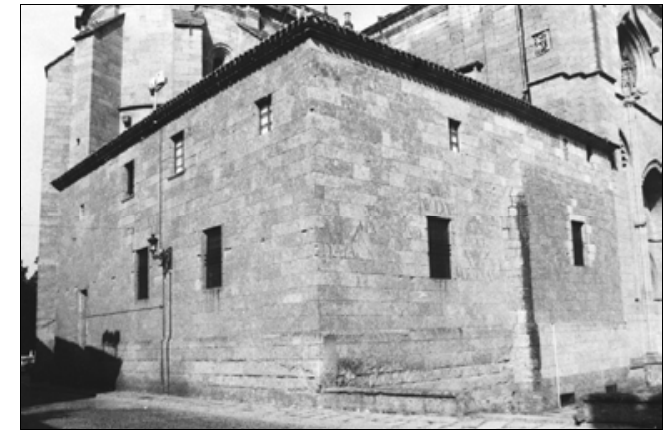

- Fig. 6. Ciudad Rodrigo. Catedral. Sacristía. Exterior.

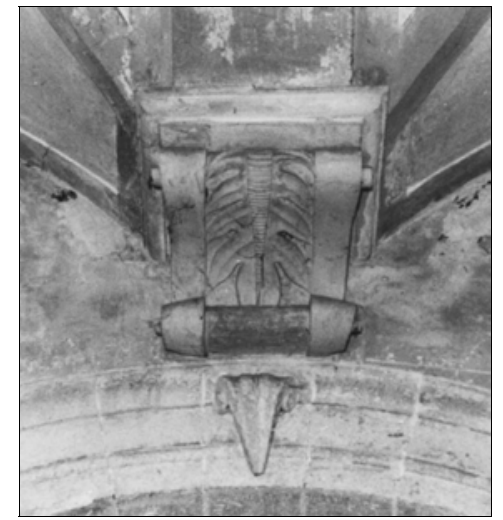

- Fig. 7. Ciudad Rodrigo. Catedral. Sacristía. Interior. Detalle.

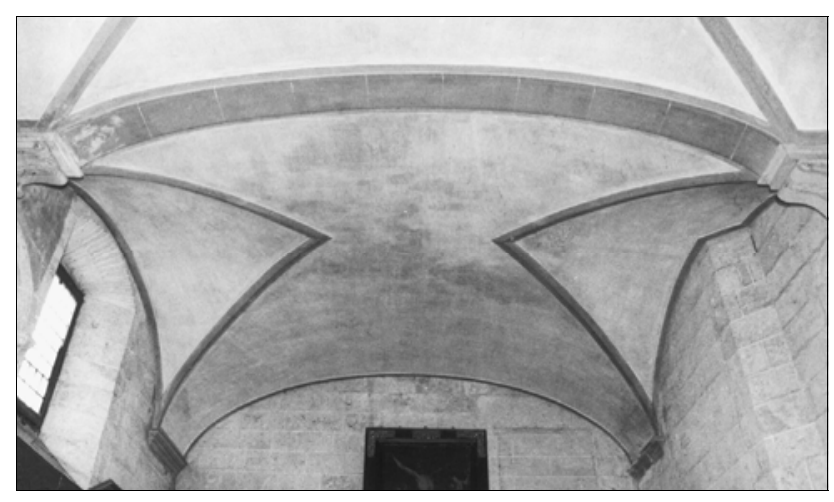

- Fig. 8. Ciudad Rodrigo. Catedral. Sacristía. Interior. 


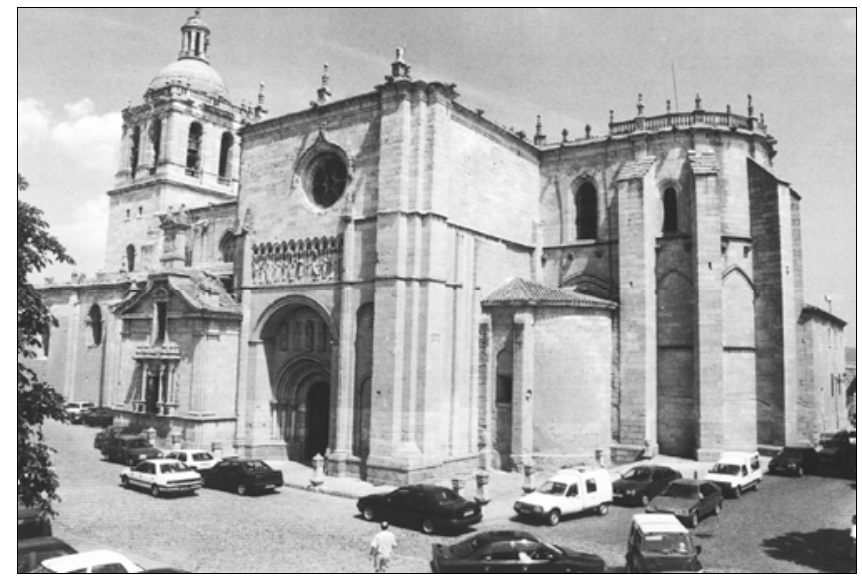

- Fig. 9. Ciudad Rodrigo. Catedral. Portada y atrio de las Cadenas.

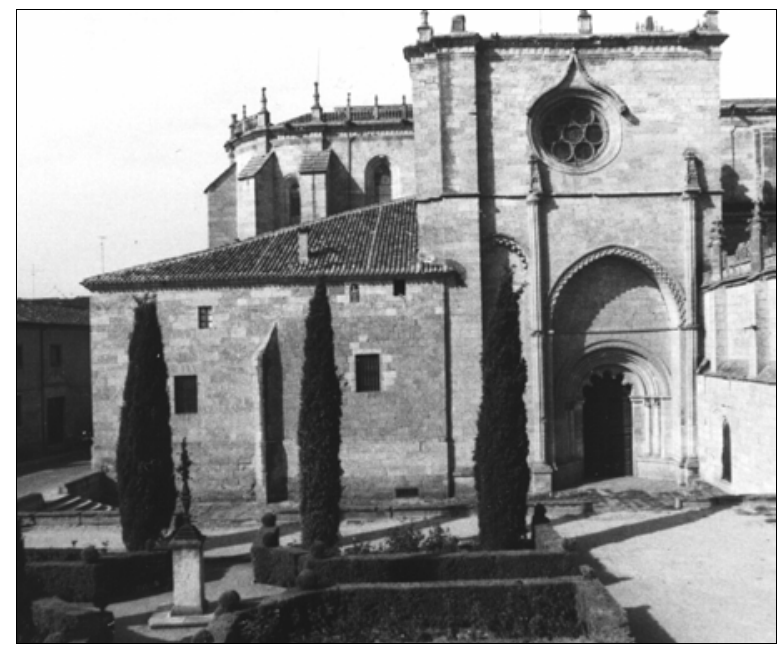

- Fig. 10. Ciudad Rodrigo. Catedral. Portada y atrio del Enlosado.

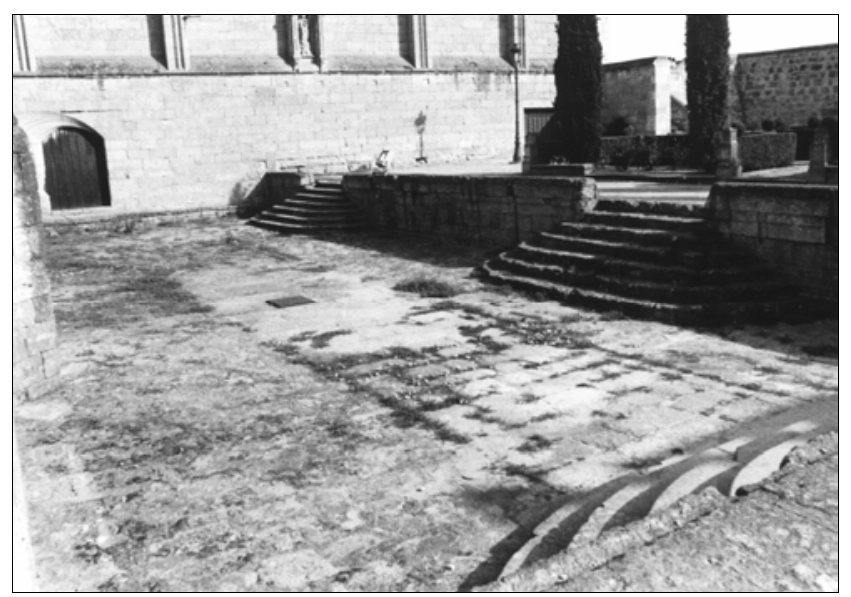

- Fig. 11. Ciudad Rodrigo. Catedral. Atrio del Enlosado. 